\title{
Resin Infiltration: A Microinvasive Treatment Option for White Spot Lesions
}

\author{
Himabindu Buddula ${ }^{1}$, Naga Sribala Gantha ${ }^{2}$, Manoj Kumar Mallela ${ }^{3}$, Srinivas Nallanchakrava ${ }^{4}$, Karunakar Parupalli ${ }^{5}$, \\ Sanjana Reddy Cheruku ${ }^{6}$
}

\begin{abstract}
Background: White spot lesions appear clinically as a first sign of enamel caries, followed by cavitation when left untreated. Number of methods and agents are available to remineralize these lesions, which include resin infiltration and casein phosphopeptide-amorphous calcium phosphate (CPP-ACP) plus agent.

Aim and objective: The aim and objective of the in vitro study was to compare microhardness of initial enamel caries using two agents (Icon and CPP-ACP Plus).

Materials and methods: 120 extracted permanent maxillary central incisors were collected. All the samples were decoronated, and crown portions of 120 samples were inserted in acrylic resin block which was prestandardized. These samples were allocated randomly into control Group I (20) and experimental Group II (100). A $4 \times 4$ mm window was created on labial surfaces of 100 samples using acid-resistant nail varnish and then demineralized to produce white spot lesions for 4 days. Then, they were allocated into five groups randomly (Group I: normal/nondemineralized enamel (control), Group Ila: demineralized enamel, Group Ilb: brushed with $0.25 \mathrm{~g}$ of non-fluoridated dentifrice (Meswak ${ }^{\mathrm{T}}$ ), Group Ilc: brushed with $0.25 \mathrm{~g}$ of non-fluoridated dentifrice + CPP ACP plus, Group Ild: ICON DMG ${ }^{\mathrm{TM}}$ resin infiltration technique, Group Ile: ICON $\mathrm{DMG}^{\mathrm{TM}}$ resin infiltration technique + brushed with $0.25 \mathrm{~g}$ of non-fluoridated dentifrice) and treated with the respective remineralizing agents for 1 month. Samples of all the groups were then subjected to microhardness test.

Results: The microhardness value of Group Ild was significantly $(p<0.001)$ high when compared to other experimental groups.

Conclusion: Resin infiltration technique showed enhancement in the microhardness of initial enamel caries lesions compared to CPP-ACP plus application.

Clinical significance: Resin infiltration technique is a microinvasive approach for increasing the microhardness of hypoplastic enamel. This may decrease need of laminates or other full coverage restorations for such teeth.
\end{abstract}

Keywords: CPP-ACP plus, Demineralization, Microhardness, Remineralization, Resin infiltration.

Journal of Operative Dentistry and Endodontics (2020): 10.5005/jp-journals-10047-0099

\section{INTRODUCTION}

Dental caries is defined as the destruction of tooth structure by acid that is generated as a by-product of bacterial metabolism in dental plaque. ${ }^{1}$ WHO reports caries prevalence was around $60-90 \%$ in children going to school, and it was almost common among adults in majority of the countries. ${ }^{2}$

White spot lesions appear clinically, which is a first sign of enamel caries. It is a subsurface area with most of the lost mineral beneath the relatively intact enamel surface. It is also known as "initial" or "incipient" lesion. It is softer than the adjacent sound enamel and is much whiter when dried with air, which precedes cavitation. In these lesions, the mineralized layer is lost. This makes the translucent enamel porous and changes its refractive index (RI). ${ }^{1}$

Remineralization is one of the noninvasive treatment options for early carious lesions, e.g., through fluoridation, improved oral hygiene, or other processes. A number of methods and agents are available to remineralize early enamel lesions. The mineralrich concentrates can be topically applied for remineralization of incipient caries lesions. These provide calcium $\left(\mathrm{Ca}^{+2}\right)$ and phosphate $\left(\mathrm{PO}_{4}^{-}\right)$ions that can easily diffuse through porous enamel in order to remineralize incipient enamel lesion. ${ }^{3}$ Milk and milk products were considered to prevent the development of caries due to the existence of casein, calcium, and phosphate contents. Later investigations on the purpose of casein and calcium phosphate concentrates on remineralization concluded that casein phosphopeptide (CPP) \begin{tabular}{l}
${ }^{1-6}$ Department of Pedodontics and Preventive Dentistry, Panineeya \\
Institute of Dental Sciences and Research Centre, Hyderabad, \\
Telangana, India \\
Corresponding Author: Naga Sribala Gantha, Department of \\
Pedodontics and Preventive Dentistry, Panineeya Institute of Dental \\
Sciences and Research Centre, Hyderabad, Telangana, India, Phone: \\
+918688802999, e-mail: drsreebala@gmail.com \\
How to cite this article: Buddula H, Gantha NS, Mallela MK, et al. Resin \\
Infiltration: A Microinvasive Treatment Option for White Spot Lesions. \\
J Oper Dent Endod 2020;5(2):83-87. \\
Source of support: Nil \\
Conflict of interest: None \\
\hline \hline
\end{tabular}

complexes stabilized the calcium phosphate and remineralized the incipient caries lesions. The combination of CPP-ACP and fluoride also brings about the remineralization of the incipient caries lesions. ${ }^{3}$

A noninvasive technique, application of CPP-ACP with fluoride (CPP-ACP Plus), is considered to be a better alternative to treat early enamel caries lesions. CPP-ACP Plus contains fluoride which helps in the formation of fluorhydroxyapatite. This complex formed is more resistant to undergo demineralization as compared to hydroxyapatite. $^{4}$

A new concept called caries infiltration to treat white spot lesions was introduced. Caries infiltration product ICON-DMG ${ }^{\text {тM }}$ was introduced in the year 2009 in Germany; it is a low-viscosity 
resin that fills, strengthens, and stabilizes demineralized enamel, without causing any damage to healthy tooth structure. It would also inhibit caries progression in initial carious lesions.

Evaluating the physical property such as hardness of initial enamel caries lesions treated with different techniques and materials will yield a better option to treat these lesions.

Remineralization of early enamel caries was studied extensively in the literature which included fluoride therapy, CPP-ACP, CPP-ACP plus application, but scarce research was focused on the evaluation of physical parameters of initial enamel caries treated with CPPACP plus and resin infiltration technique. Hence, the purpose of the present study was to measure the effect of resin infiltration technique and CPP-ACP Plus on the microhardness of initial enamel caries lesions.

\section{Materials and Methods}

The present study was conducted in the Department of Paediatrics and Preventive Dentistry, Panineeya Institute of Dental Sciences and Hospital, Hyderabad, Telangana, India. A total of 120 maxillary central incisors which were extracted due to diseases of periodontium were collected for the study.

Teeth with decay, infractions, and filled were excluded. These samples were thoroughly cleaned using an ultrasonic scaler, and $0.1 \%$ thymol solution was used as storage media to avoid dehydration of the samples until the study was commenced.

\section{Preparation of Samples}

120 samples were decoronated at cementoenamel junction with the help of a diamond disk, and the crown part of each sample was embedded in a $1.2 \times 1 \mathrm{~cm}$ thick acrylic resin block. Labial surfaces of each sample were abraded in order to obtain flat enamel surface.

Samples were randomly divided as follows. Computer randomization was carried out. Concealment and allocation was done.

Control Group I: All 20 samples were subjected to microhardness test to get the baseline values of untreated sound enamel.

\section{Creating Window}

On the labial surface of the samples, a $4 \times 4 \mathrm{~mm}$ window was created using a template made on a sticker paper. This template was attached to the labial surface of the samples to prevent any loss of nail varnish. Template is then removed to expose the window (Fig. 1A).

The demineralization regimen followed was similar to the one conducted by Patil and Anegundi. ${ }^{5}$ For preparing demineralizing solution, lactic acid of $0.1 \mathrm{M}$, calcium chloride $\left(\mathrm{CaCl}_{2}\right)$ of $3 \mathrm{Mm}$, and potassium dihydrogen phosphate of $1.8 \mathrm{Mm}$ and $40 \%$ sodium hydroxide $\left(\mathrm{Na}(\mathrm{OH})_{2}\right)$ (SD Fine Chem Limited ${ }^{\mathrm{TM}}$ ) were mixed, and $\mathrm{pH}$ was adjusted to 4.5 .

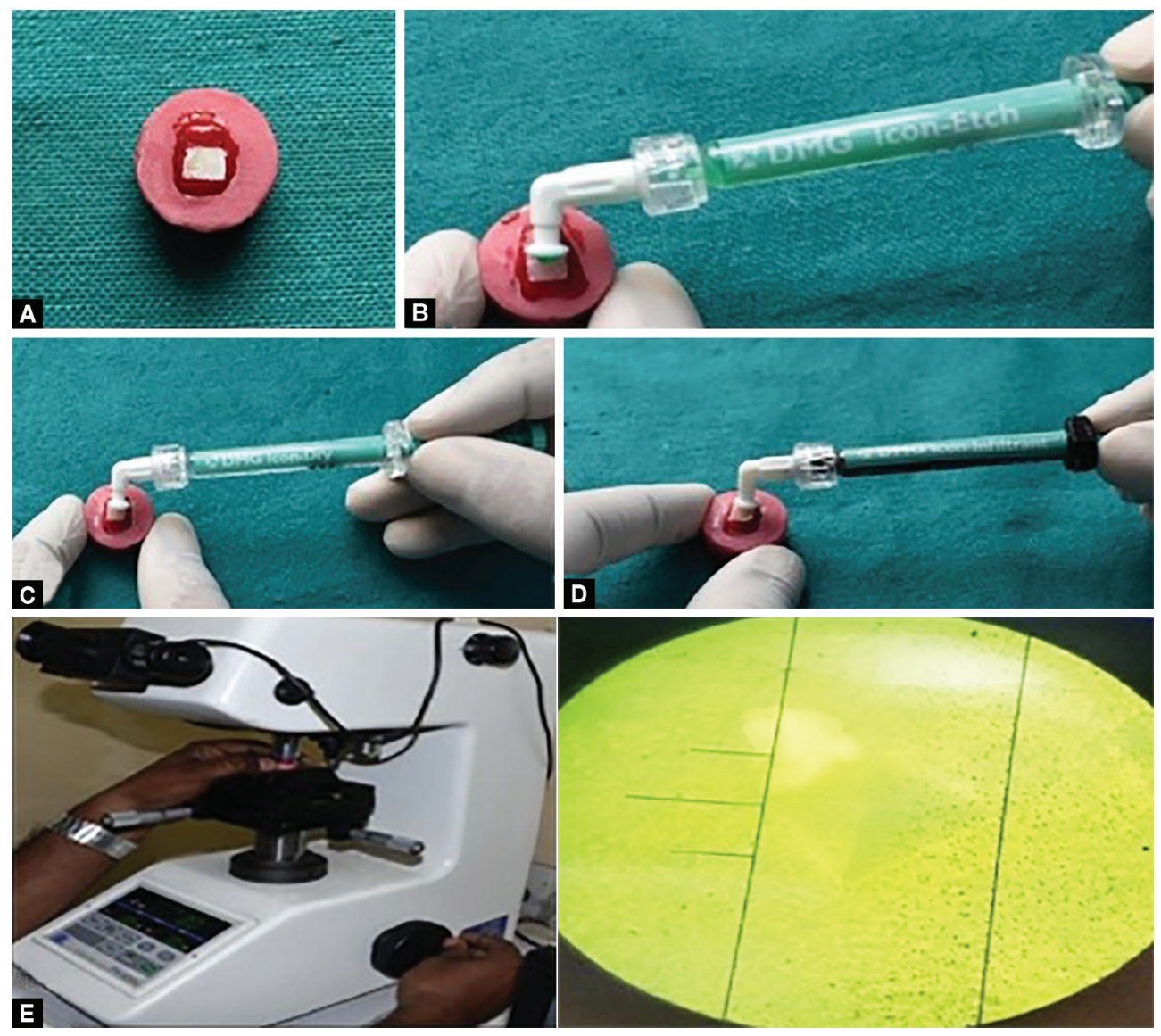

Figs 1 A to E: Description of procedure showing the application of resin infiltrate. (A) $4 \times 4 \mathrm{~mm}$ window; (B) ICON etchant application; (C) ICON dry application; (D) ICON infiltrant application; (E) Microhardness testing 
The artificial saliva was prepared by mixing $3.90 \mathrm{mM}$ trisodium phosphate, $4.29 \mathrm{mM}$ sodium chloride $(\mathrm{NaCl}), 17.98 \mathrm{mM}$ potassium chloride $(\mathrm{KCl}), 1.10 \mathrm{mM}$ calcium chloride $\left(\mathrm{CaCl}_{2}\right), 0.08 \mathrm{mM}$ magnesium chloride $\left(\mathrm{MgCl}_{2}\right), 0.50 \mathrm{mM}$ sulfuric acid $\left(\mathrm{H}_{2} \mathrm{SO}_{4}\right)$, $3.27 \mathrm{mM}$ sodium carbonate $\left(\mathrm{Na}_{2} \mathrm{CO}_{3}\right)$ (SD Fine Chem Limited ${ }^{\mathrm{TM}}$ ), and distilled water, with $\mathrm{pH}$ 7.2. The prepared artificial saliva was stored in an amber-colored plastic bottle at room temperature in a cool dark place.

The 100 samples were immersed for a period of 4 days at $37^{\circ} \mathrm{C}$ temperature in demineralizing agent to produce white spots on the enamel surface. This is followed by through washing with deionized water and dried. The exposed areas were inspected for chalky white appearance. These were then divided randomly into five experimental groups. The artificial saliva was replenished every 24 hours for 1 month in all the groups.

Group lla: After demineralization, the samples were placed in artificial saliva at room temperature and tested for microhardness.

Group IIb: Samples were brushed with a $0.25 \mathrm{~g}$ of non-fluoridated dentifrice (Meswak ${ }^{\mathrm{TM}}$, Dabur India Limited, New Delhi) using JSB ${ }^{\mathrm{TM}}$ Oral Care HF 128 kids musical electronic tooth brush with oscillating bristles for 2 minutes once daily and later stored in artificial saliva.

Group I/c: Samples were brushed with same $0.25 \mathrm{~g}$ of non-fluoridated dentifrice using the similar electronic tooth brush for 2 minutes once daily, and then, the samples were treated by placing 0.5 - $\mathrm{mm}$-thick layer of CPP-ACP Plus (GC Tooth Mousse Plus ${ }^{\circledR}$ ) on the surface and left without disturbing them for 3 minutes. After this, CPP-ACP Plus was wiped off with cotton and samples were transferred to artificial saliva.

Group IId: Samples were treated with ICON DMG ${ }^{\mathrm{TM}}$ resin infiltration technique. For 2 minutes, Icon Etch was applied (Fig. 1B) and then washed with water for 30 seconds. Later, samples were air-dried, and then Icon Dry was applied for 30 seconds (Fig. 1C), which is again rinsed with water and dried. After this, Icon Infiltrant was applied twice -3 minutes for first time and 1 minute for second time (Fig. 1D). Samples were subjected to light cure for 40 seconds and then stored in artificial saliva.

Group Ile: Samples were treated as per the manufacturer's instructions with resin infiltration technique and brushed with same $0.25 \mathrm{~g}$ of non-fluoridated dentifrice for 2 minutes every day using electronic tooth brush and later were stored in artificial saliva.

All the above-mentioned procedures were repeated for 1 month. All 100 samples were rinsed thoroughly in deionized water, blotted dry, and mounted on the indentation table of the microhardness tester (FM-300e) (Fig. 1E). Area of the enamel to be indented was evaluated under a light microscope with camera, which was attached to the microhardness tester. For microhardness evaluation, a load of $100 \mathrm{~g}$ was applied for 10 seconds, five indentations at least $100 \mu \mathrm{m}$ apart were made at center of each sample, and then average was calculated and the values were tabulated, which were subjected to statistical analysis.

\section{Statistical Analysis}

The data thus obtained was entered in an excel data sheet and statistically analyzed with SPSS software version 22 . The values were observed to be statistically significant at $95 \%$ confidence interval and $P$ value $<0.05$. The pairwise comparisons between all the groups were carried out using post hoc test.

\section{Results}

On statistical evaluation of microhardness values $(\mathrm{VHN})$, a significant difference was observed between Group I (371.38 \pm 39.3 VHN) and Ila $(267.84 \pm 11.4 \mathrm{VHN})\left(p<0.00001^{*}\right)$. Similarly, on intergroup comparison of microhardness values (VHN), significant difference was observed between Group IIb (267.63 $\pm 10 \mathrm{VHN})$ and IIC $(326.9 \pm 16.4 \mathrm{VHN})\left(p<0.0001^{*}\right)$. On evaluation of microhardness values between Group Ild $(368.01 \pm 8.4 \mathrm{VHN})$ and Ile $(330.3 \pm 20.6$ VHN), there was significant difference $\left(p<0.0001^{*}\right)$. However, on comparison of overall mean microhardness values, Group I $(371.38 \pm 39.3 \mathrm{VHN})$ and IId $(368.01 \pm 8.4 \mathrm{VHN})$ showed higher microhardness compared to other groups (Table 1).

The observation showed no statistically significant $(p=0.995)$ difference in microhardness value between Group Ild and I, Group Ila and IIb, and Group Ilc and Ile. The microhardness value of Group Ild was highly significant $(p<0.001)$ when compared to all other experimental groups (Table 2).

\section{Discussion}

Early enamel lesions present an evidently intact outer layer, followed by body of the lesion which is a subsurface porous area. The porosities present in these lesions are filled with either water or air. Surrounding light which falls on the teeth is deflected and scattered. This is due to the difference between the RI of sound enamel (RI:1.62) and that of water (RI:1.33) or that of air (RI:1.0) within the body of the lesion, thus making the initial lesion appear opaque after dessication. ${ }^{6}$

In the present study, maxillary permanent central incisors were included due to their wide surface area of enamel. The enamel thickness was more in the mid-coronal region than in cervical region, and incisal surfaces and flat surfaces were required for microhardness testing. ${ }^{7}$ Thus, mid-coronal region was chosen for the window preparation.

Demineralization of the samples was carried out to create the initial enamel carious lesions. The $\mathrm{pH}$ was set at 4.5 for demineralizing solution in order to replicate the demineralization processes that occur in vivo below the critical $\mathrm{pH}^{5}$ In order to maintain constant $\mathrm{pH}$ of the demineralizing solution, it was changed every 12 hours.

Artificial saliva was changed every 24 hours throughout the period of remineralization, to guarantee ionic balance and maintain $\mathrm{pH}^{8}$

Studies have shown that remineralization of small lesions with low-dose fluoride therapy was more efficient. ${ }^{9}$ Usage of low fluoride concentration $(0.2 \%$ or $900 \mathrm{ppm}$ of sodium fluoride $(\mathrm{NaF})$ ) leads to complex localization of free $\mathrm{Ca}^{+2},(\mathrm{PO})_{4}{ }^{2-}$, and fluoride ions, which help in maintaining a supersaturated state by repressing demineralization.

ICON-DMG ${ }^{\mathrm{TM}}$ resin infiltrant used in this study consists of three components, namely, Icon Etch containing 15\% hydrochloric acid (HCL), Icon Dry containing 99\% ethanol, and Icon infiltrant. The itching of enamel surface with $15 \% \mathrm{HCL}$ causes deep surface porosities, leading to deeper penetration of the resin. ${ }^{10}$ Acid conditioning with $15 \% \mathrm{HCL}$ enhanced the penetration of resin compared with $37 \%$ phosphoric acid gel. ${ }^{11}$

ICON Dry, which contains $99 \%$ of ethanol, was administered for 30 seconds before the application of infiltrant, thus facilitating 


\begin{tabular}{|c|c|c|c|c|c|c|}
\hline S. No. & Group I & Group IIa & Group IIb & Group IIc & Group IId & Group lle \\
\hline 1 & 439.3 & 267.4 & 253.4 & 350.2 & 368.9 & 300.0 \\
\hline 2 & 315.3 & 288.4 & 283.7 & 299.9 & 372.6 & 359.3 \\
\hline 3 & 371.2 & 252.2 & 262.4 & 315.6 & 369.6 & 320.1 \\
\hline 4 & 350.1 & 260.1 & 270.2 & 325.6 & 350.5 & 309.5 \\
\hline 5 & 383.6 & 271.3 & 268.3 & 342.8 & 379.3 & 360.2 \\
\hline 6 & 430.2 & 263.4 & 252.4 & 349.3 & 365.2 & 302.1 \\
\hline 7 & 310.1 & 285.4 & 280.2 & 302.2 & 375.2 & 357.3 \\
\hline 8 & 372.2 & 258.2 & 265.5 & 319.6 & 367.6 & 320.4 \\
\hline 9 & 353.3 & 262.2 & 271.3 & 323.4 & 355.4 & 310.2 \\
\hline 10 & 386.2 & 270.1 & 269.4 & 345.1 & 378.2 & 359.2 \\
\hline 11 & 374.4 & 267.2 & 281.6 & 321.4 & 366.2 & 358.5 \\
\hline 12 & 325.2 & 275.1 & 264.4 & 347.2 & 374.5 & 325.6 \\
\hline 13 & 345.6 & 255.2 & 267.3 & 310.2 & 370.4 & 315.7 \\
\hline 14 & 385.4 & 286.2 & 271.2 & 321.4 & 351.4 & 352.4 \\
\hline 15 & 425.2 & 256.2 & 251.3 & 342.7 & 376.2 & 309.4 \\
\hline 16 & 436.3 & 280.4 & 266.4 & 342.3 & 357.2 & 324.5 \\
\hline 17 & 318.3 & 275.4 & 280.6 & 337.5 & 369.2 & 336.2 \\
\hline 18 & 365.2 & 248.2 & 268.1 & 317.2 & 367.2 & 324.2 \\
\hline 19 & 356.1 & 264.1 & 274.4 & 306.2 & 369.2 & 330.2 \\
\hline 20 & 383.6 & 270.2 & 250.5 & 318.2 & 376.2 & 331.1 \\
\hline Mean \pm SD & $371.38 \pm 393$ & $267.84 \pm 11.4$ & $267.63 \pm 10$ & $326.9 \pm 16.4$ & $368.01 \pm 8.4$ & $330.3 \pm 20.6$ \\
\hline$p$-value & $<0.00001^{*}$ & $<0.0001^{*}$ & $<0.0001^{*}$ & $p$-value & $<0.00001^{*}$ & $<0.0001^{*}$ \\
\hline
\end{tabular}

*very significant

Table 2: Pairwise comparison of microhardness values among groups

\begin{tabular}{|c|c|c|c|c|c|c|}
\hline Group & Group I & Group Ila & Group IIb & Group I/c & Group IId & Group lle \\
\hline Group I & 0 & $<0.001^{*}$ & $<0.001^{*}$ & $<0.001^{*}$ & $0.996 \mathrm{NS}$ & $<0.001$ \\
\hline Group Ila & $<0.001^{*}$ & 0 & $1.00 \mathrm{NS}$ & $<0.001^{*}$ & $<0.001^{*}$ & $<0.001^{*}$ \\
\hline Group IIb & $<0.001^{*}$ & 1.00 NS & 0 & $<0.001^{*}$ & $<0.001^{*}$ & $<0.001^{*}$ \\
\hline Group Ilc & $<0.001^{*}$ & $<0.001^{*}$ & $<0.001^{*}$ & 0 & $<0.001^{*}$ & 0.995 NS \\
\hline Group Ild & 0.995 NS & $<0.001^{*}$ & $<0.001^{*}$ & $<0.001^{*}$ & 0 & $<0.001^{*}$ \\
\hline Group lle & $<0.001^{*}$ & $<0.001^{*}$ & $<0.001^{*}$ & $0.995 \mathrm{NS}$ & $<0.001^{*}$ & 0 \\
\hline
\end{tabular}

NS, not significant; *very significant

the drying process. ${ }^{11}$ In a study conducted by Paris et al., ${ }^{12}$ it was concluded that ethanol was linked with greater penetration coefficient of the resin by decreasing the viscosity and contact angle so it can be helpful in rapid penetration of resin. Higher penetration coefficient and satisfactory hardening were also noticed and proved to be present in mixtures containing large amounts of triethylene glycol dimethacrylate, 2-hydroxyethyl methacrylate, and ethanol.

Infiltrating resin in ICON-DMG ${ }^{\mathrm{TM}}$, containing triethylene glycol dimethacrylate, is light cured and has low viscosity. This property aids in creeping the material deep into the active lesion with the aid of capillary forces and forms a diffusion barrier. Hence, this technique is proved to be efficient. ${ }^{10}$

In the present study, digital display Vickers hardness test was used at a load of $100 \mathrm{~g}$ along with a diamond indenter for 10 seconds. The lowest load of $100 \mathrm{~g}$ for enamel was selected because it created Vickers diagonals longer than $20 \mu \mathrm{m}$, which was recommended to prevent errors in optical measurement. The duration of indentation was fixed to 10 seconds, because this was sufficient for indentation on the tooth surface permanently. ${ }^{13}$

Group lla (demineralized enamel) showed lower mean microhardness value (267.84 VHN), compared with the Group I (sound enamel $371.38 \mathrm{VHN}$ ), and there was highly significant $(<0.00001)$ difference between Group I and Group Ila.

Crombie et al. concluded that the polycrystalline structure of hypomineralized enamel was extremely porous and unorganized than normal enamel with a report of $28 \%$ reduction in mineral content, with elevations in protein content up to 3-15-fold, and also with $80 \%$ more carbonated apatite; thus, the hypomineralized enamel hardness was significantly lower than sound enamel. ${ }^{14}$

The mean microhardness value of Group Ild (resin infiltration technique, $368.01 \mathrm{VHN}$ ) was similar to that of Group I (sound enamel, $371.38 \mathrm{VHN}$ ). This proves that resin infiltrated enamel microhardness is almost equal to the sound enamel.

Resin infiltrant resulted in high score of mean microhardness, which is because of the gaps filled by the material that enhanced the strength of the tooth structure. ${ }^{1}$ 
Paris et al. stated that twice application of infiltrant was shown to enhance microhardness of lesions infiltrated with resin. It is therefore possible that twice application of resin might fill porosities and crevices within the infiltrated lesion body and compensate polymerization shrinkage, thus increasing hardness and decreasing mineral loss when challenged again by demineralization. ${ }^{7}$

Group lle showed lesser microhardness value compared to Group Ild. This could be attributed to the slight but significant mineral loss during brushing with non-fluoridated dentifrice. ${ }^{15}$

When Group Ilc and Group Ild were compared, the samples treated with resin infiltration showed significantly $(P<0.0001)$ higher microhardness. This might be due to the fact that lowviscosity resin could reach the deeper areas of the initial enamel caries lesion immediately after the treatment.

Shimaa et al. ${ }^{8}$ concluded in the in vitro study conducted that the resin infiltration had the highest depth of penetration with Icon that resulted in higher microhardness, which is statistically significant compared with CPP-ACP Plus. The results obtained in this study were in agreement with the present study.

The present study suggested that resin infiltration can be observed as microinvasive treatment option for initial enamel caries lesions as it showed maximum microhardness and depth of penetration. This microinvasive technique for the treatment of initial enamel caries not only provides therapeutic benefits but also significantly reduces both long-term restorative needs and costs, thus encouraging the concept of minimum intervention dentistry. However, the present study acknowledges certain limitation such as chemical makeup of dental resins that favor absorbing liquids. Therefore, discoloration of resin may be inevitable over time.

\section{Conclusion}

Based on the results of present study, it could be concluded that:

- The microhardness of resin-infiltrated carious enamel was almost the same as that of microhardness of sound enamel.

- Resin infiltration technique enhanced the microhardness of initial enamel caries lesions compared with CPP-ACP Plus application.

- The decrease in microhardness of initial enamel caries lesions treated with resin infiltration technique followed by brushing may be because of significant mineral loss due to brushing.

\section{Clinical Significance}

Resin infiltration technique is a noninvasive or a microinvasive approach for increasing the microhardness of hypoplastic enamel. This technique may decrease the need of laminates or other full coverage restorations for such teeth.

\section{ACKnowledgment}

We acknowledge the support of ICON-DMG ${ }^{\mathrm{TM}}$ for providing us the valuable material required for this study.

\section{References}

1. Torres CR, Rosa PC, Ferreira NS, et al. Effect of caries infiltration technique and fluoride therapy on microhardness of enamel carious lesions. Oper Dent 2012;37:363-369. DOI: 10.2341/11-070-L.

2. Petersen $\mathrm{PE}$, Bourgeois $\mathrm{D}$, Ogawa $\mathrm{H}$, et al. The global burden of oral diseases and risks to oral health. Bull World Health Organ 2005;83:661-669. PMID: 16211157 PMCID: PMC2626328

3. Mehta R, Nandlal B, Prashanth S. Comparative evaluation of remineralization potential of casein phosphopeptide-amorphous calcium phosphate and casein phosphopeptide-amorphous calcium phosphate fluoride on artificial enamel white spot lesion: an in vitro light fluorescence study. Indian J Dent Res 2013;24:681-689. DOI: 10.4103/0970-9290.127610.

4. Ladhani ZH, Dargad S, Dixit V, et al. Effect of application of remineralizing agents on the microhardness of microabraded teeth. World J Dent 2015;6(3):174-177. DOI: 10.5005/jp-journals-10015-1337.

5. Patil VH, Anegundi RT. An in vitro assessment of fluoride uptake by tooth enamel from four different fluoride dentifrices. Eur Arch Paediatr Dent 2014;15:347-351. DOI: 10.1007/s40368-014-0122-3.

6. Gugnani N, Pandit IK, Gupta M, et al. Caries infiltration of noncavitated white spot lesions: a novel approach for immediate esthetic improvement. Contemp Clin Dent 2012;3:199-202. DOI: 10.4103/0976237X.101092.

7. Mandava J, Reddy YS, Kantheti S, et al. Microhardness and penetration of artificial white spot lesions treated with resin or colloidal silica infiltration. J Clin Diagn Res 2017;11:142-146. DOI: 10.7860/ JCDR/2017/25512.9706.

8. Kamath P, Nayak R, Kamath SU, et al. A comparative evaluation of the remineralization potential of three commercially available remineralizing agents on white spot lesions in primary teeth: an in vitro study. J Indian Soc Pedod Prev Dent 2017;35:229-237. DOI: 10.4103/JISPPD.JISPPD_242_16.

9. Pai D, Bhat SS, Taranath A, et al. Use of laser fluorescence and scanning electron microscope to evaluate remineralization of incipient enamel lesions remineralized by topical application of casein phosphopeptide amorphous calcium phosphate (CPP-ACP) containing cream. J Clin Pediatr Dent 2008;32:201-206. DOI: 10.17796/ jcpd.32.3.d083470201h58m13.

10. El-Zankalouny SM, El Fattah WMA, El-Shabrawy SM. Penetration depth and enamel microhardness of resin infiltrant and traditional techniques for treatment of artificial enamel lesions. Alex Dent J 2016;41:20-25. http://dx.doi.org/10.21608/adjalexu.2016.59167.

11. Aravindkumar A, Mahewsari U, Kingston C, et al. Caries-preventive efficacy of resin infiltrant, casein phosphopeptide-amorphous calcium phosphate and nanohydroxyapatite using confocal scanning electron microscope: an in vitro study. J Oper Dent Endod 2017;2:610. DOI: $10.5005 /$ jp-journals-10047-0025.

12. Paris $S$, Schwendicke F, Seddiq $S$, et al. Micro-hardness and mineral loss of enamel lesions after infiltration with various. J Dent 2013;41:543-548. DOI: 10.1016/j.jdent.2013.03.006.

13. Chuenarrom C, Benjakul P, Daosodsai P. Effect of indentation load and time on Knoop and Vickers microhardness tests for enamel and dentin. Mater Res 2009;12(4):473-476. DOI: 10.1590/S1516-14392009000400016.

14. Crombie FA, Manton DJ, Palamara JE, et al. Characterization of developmentally hypomineralized human enamel. J Dent 2013;41(7):611-618. DOI: 10.1016/j.jdent.2013.05.002.

15. Hayasaki H, Saitoh I, Nakakura-Ohshima K, et al. Tooth brushing for oral prophylaxis. Jpn Dent Sci Rev 2014;50:69-77. DOI: 10.1016/ j.jdsr.2014.04.001. 